\title{
A field study with primary school children on perception of social presence and interactive behavior with a pet robot
}

\author{
Marcel Heerink, Marta Díaz, Jordi Albo-Canals, Cecilio Angulo, Alex Barco, Judit Casacuberta and \\ Carles Garriga
}

\begin{abstract}
This paper presents a study on measuring (1) how children experience a pet robot, (2) how they play with it and (3) how children's perceptions on and interaction with pet robots are interrelated. The study features different types of subjective and objective techniques to assess the degree of perceived social entity from self-reports (i.e. questionnaires) and observed behavior. Three short questionnaires and an ad hoc code scheme of 15 low-level micro-behaviors were developed. 28 scholars aged 8 to 12 were observed at school during a play period with a Pleo robot and asked to answer the questionnaires. We found that the different questionnaire based methods were in line each other. Therefore, anyone of them can be used to measure the experience of a social entity. Play analyses showed that the two most prevalent behaviors were clearly social: petting the robot and showing it objects to engage in interaction. Moreover, children spent on average less than one per cent of the session time treating the robot as an artifact. However, significant covariation between the experience of a social entity and observed behavior could not be established.
\end{abstract}

\section{INTRODUCTION}

In the last decennia robots have been used effectively in therapy and educational interventions with primary school children. They are for example been used for therapy and educational interventions: with autistic children [1-4], with children with motor and physical impairments [5] and long term hospitalized children ([6-8]), and also in educative activities [9-11]

In different contexts it has been established that the effectiveness of a robot can be related to the way it is experienced $[12,13]$. Usually this simply means that is is more effective in a therapeutic or educational sense, when it is liked more. Of course, this is the case with technology in general $[14,15]$ but robotic systems differ from other technologies, because they concern technology that is not always perceived just as such: a robot can be (partly) perceived as a social actor, and it could be that interaction with it follows the same

*Research supported by the Spanish Ministry of Science and Education through the project SOFIA (TIN2011-28854-C03-01,03)

J. Albo-Canals, A. Barco, and C. Garriga are with LIFAELS La Salle, Ramon Llull University, Barcelona, SPAIN (e-mail: abarcomartelo@gmail.com, jalbo@salle.url.edu, cgarriga@salle.url.edu)

C. Angulo, J. Casacuberta, M. Díaz are with CETpD Technical Research Center for Dependency Care and Autonomous Living UPC Technical University of Catalonia, Edifici Neapolis, Rbla. Exposició, 59-69, 08800 Vilanova i la Geltrú Barcelona SPAIN (e-mail: \{marta.diaz; judit.casacuberta; cecilio.angulo\}@upc.edu)

M. Heerink, is with the Robotics Center of the Windesheim Flevoland University of Applied Sciences, Almere, The Netherlands (e-mail: m.heerink@windesheimflevoland.nl) principles as interpersonal communication rather than those of human-machine interaction. This is often found to show in the behavior of people interacting with robots ([16]. This can be measured both by questionnaires and behavior analysis. With children however, both these types of measurement are not necessarily appropriate: their answering and behavioral patterns are different in many aspects $[17,18]$.

Since we are planning research projects on different types of primary school children target groups, we are interested in developing methods that can be used to establish how they view and experience different types of robots in different states and how this experience is reflected in their behavior. A next step could be to relate the results to the effectiveness of robot assisted therapy or educational use of a robot.

In this study we use three different questionnaire based methods: a social presence based questionnaire, an exercise on adding (selecting) adjectives and a questionnaire on social skills attributions and emotional attachement. Subsequently we will establish if observed behavior of the participants can be related to the results of these questionnaires. After discussing related work, we will describe the field study where we used these methods and subsequently we will present the results, conclusion and discussion.

\section{RELATED WORK}

\section{A. Children-PetRobot Interaction}

Recently, pet like robots have been introduced to reproduce thee social and emotional benefits associated with the interaction and the emotional bond between children and companion animals such as entertainment, relief, support and enjoyment. The relationship between master and pet is based on hierarchy and attachment. According to these two dimensions, it is assumed that a sort of master-pet bond may emerge between a child and a pet robot with social skills. Hierarchy means that children have an obvious higher status that could be enhanced if the pet robot has a baby appearance [8]. The social situation, defined by the master/pet interdependence, will naturally produce engaging activities like expressions of affection and concern (i.e. petting, grooming) and interactive purposeful activities that implies request for reciprocity such as teaching new skills, giving orders, demanding attention.

In this context the robot - besides considerations of appearance, mainly life-like and baby-like features must be able to deploy (or acquire) social skills for effective communication (i.e. orientation, attention, responsiveness), for hierarchy submission (i.e. recognition, obedience), and to express and generate attachment (i.e. affective expressiveness). 
An exploratory study with primary school children first at school and then in the lab, reports that Pleo generates in children needs-oriented affective behavior, like giving affection and caretaking. Children expect animal-like behaviors such as 'making sounds' and eating, and attribute Pleo animal characteristics such as internal drives (e.g., sleepiness, anger, hunger), reasoning and intention. In the lab session, children resumed the relationship and reinforced the initial social bond built during their previous experience at school. Children asked for their baby dinosaur - the one they met at school - and interpret Pleo's responses [7] as signs of recognition.

\section{B. Social presence and social activity}

Since it is not unusual for humans to treat systems and devices as social beings [19], it seems likely that humans treat embodied agents as such. The extent to which they do so seems to be related to a factor that is often related to as either 'Presence' or, more specifically 'Social presence'. Many research projects that are related to robot user experiences incorporate this concept [20-23] .

The term presence originally refers to two different phenomena. First, it relates to the feeling of really being present in a virtual environment and can be defined as 'the sense of being there' [24]. Second, it can relate to the feeling of being in the company of a social entity: 'the perceptual illusion of non mediation' [25]. In our context, the second definition is relevant. The experience of presence of a social entity usually shows by a higher rate and intensity of expressions that a speaker uses [26,27]. It demonstrates the amount of conversational engagement one feels [28].

The analyzed behavior is sometimes called conversational expressiveness: the amount and intensity of facial expressions and gestures when engaged in a conversation. A study by [29] Heerink et al. in 2009 established that for elderly users a higher score on the construct of social presence did correlate with a higher score on conversational expressiveness. As in earlier research [30], it was found that a higher score on social presence correlated with a higher score on acceptance (as indicated by the expressed intention to use the system), the behavior analysis could also be used as a predictive indication for robot acceptance.

Furthermore, the level of social presence is assumed to have an effect on interaction activities. Purposeful activities that implies considering the robot as a social partner are supposed to be facilitate by strong feelings of social presence. On the contrary, low-levels of social presence are expected to produce less social behavior and more treating the robot as a tool or an artifact.

\section{METHOD}

\section{A. Procedure and setting}

\section{1) Robot}

The pet-like robot $\mathrm{Pleo}^{1}$ has been selected for the trials with primary school children. Pleo is a robot platform, imitation of a Camarasaurus dinosaur, that exhibits an appealing baby-likeness, expressiveness, and an array of different behavior and mood modes. Pleo is a commercial

\footnotetext{
${ }^{1}$ www.pleoworld.com
}

entertainment platform developed by Innvo Labs. It is equipped with different tactile sensors beneath its skin, ground sensors in the feet, speakers and microphones. It features also a pet like personality which develops in time, internals drives like hunger or sleep, and several mood modes: happy, extremely scared, and curious. Pleo has been tested in several research works $[31,32,8$. These studies focused on the effect of Pleo in long-term interaction, especially with children. More specifically, [33] conducted a study with six families which were given a Pleo for a minimum of two months and a maximum of ten. Similarly, [34] carried out a study based on the opinions of blog users about Pleo. Although results show a wearing out of the novelty effect and diminishing care behaviors, most of the studies identified the development of a social bond with the robot.

\section{2) Participants}

28 children (9 girls and 19 boys) in groups of two, aged between 6 and 12 participated in the trials. The participants were recruited from the attendants to a robotic workshop carried out in a weekly basis during the term as a complementary subject they had chosen voluntarily. The participation in the trials was introduced as an optional activity in the workshop. Provided there were more volunteers than required, the selection was made according to performance in a previous task as a reward. Moreover, in the second day girls were preferred to balance the group.

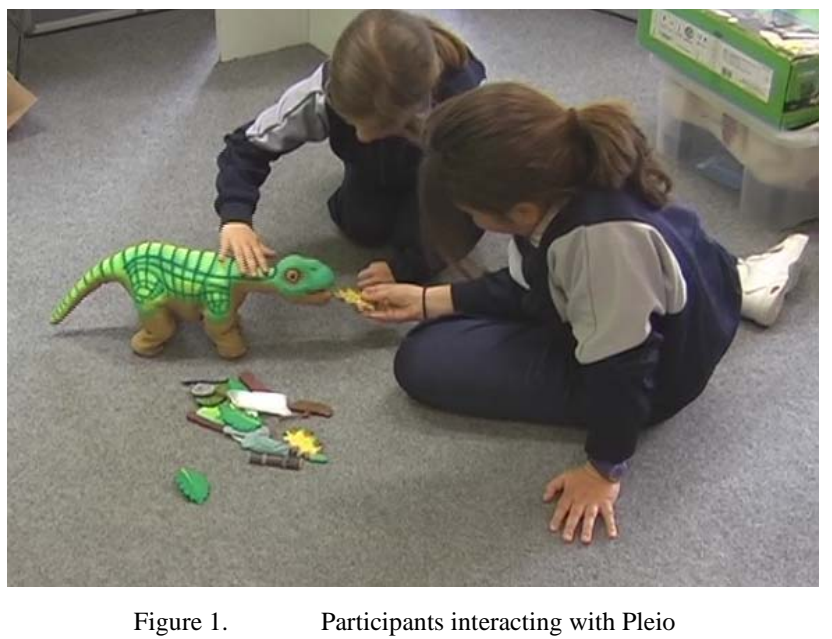

\section{3) Design and procedure}

The trials were designed as a free play session to observe the spontaneous and unconstrained interaction with the robot. The experience was designedas aplay in couples, thus enhancing verbal communication to complement the behavioral data analyses. The play sessions were carried out in a separated circular area in a service room. The play area was delimited with walls with windows allowing the experimenters to observe the play from outside the play area.

The conductor, who was a familiar teacher, brought the couple from the regular classroom to the observation area with the only instruction to play with Pleo for a while. In the play area they found the Pleo on the floor in on position and 
several pieces of Pleo's toys and food scattered besides it (i.e. a sugar cane, a chunk of ice, the ID card, six learning stones, 6 leaves of 4 different kinds, a rock salt, and the Tug of War). The conductor moved away and the children were left alone for 8 minutes. Neither the conductor nor the other experimenters initiated any interaction with the children. When addressed by the children, the conductor would respond in a deliberate neutral way. The only conductor intervention that occurred was when PLEO's entered the sleep mode and had to be awakened.

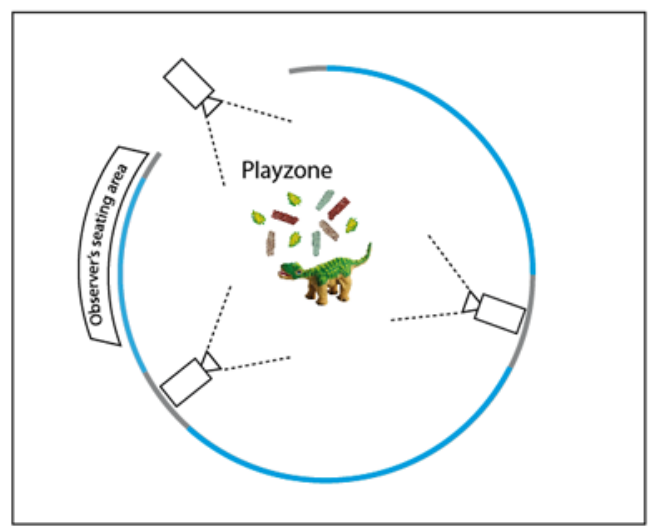

Figure 2. The play scenario and the observation setting

When the play time was over, the conductor entered the play area, told the children that the play session was over, turned off the robot and instructed them to answer some questions about the session with the experimenters.

Two observers stayed outside the play area and observed the trial trough the window, takingnotes of any relevant contextual information. The play session was video recorded with three cameras for further analyses (Fig. 2).When the play finished they help the children to answer the questionnaire individually.

The whole experimental session took15 minutes for each couple including the questionnaires.

4) Questionnaires and interviews

We used three different types of questionnaires to establish the sense of presence. First we used a social presence questionnaire, adapted from the questionnaire that was used in earlier research in which observed user behavior was linked to social presence. This questionnaire features statements that can be responded to on a 5 point Likert scale and was derived from the social presence questionnaire developed by Bailenson et al. [35].

TABLE I.

$$
\text { QUESTIONNAIRE }
$$

SOCIAL PRESENCE

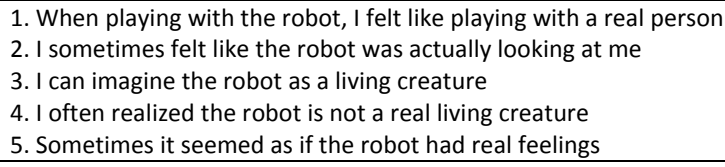

A second method featured the attribution of adjectives. This methodology is used in different types of research to establish a subjects perception of an artifact [36,37]. We created a list of 20 words that could be used to describe the robot. Half of these words were referring to a social entity: kind, unkind, polite, rude, naughty, clever, stupid, angry, impatient and patient. The other ten words were more 'material', describing mechanical toys or devices: useful, useless, easy, simple, complex, breakable, solid, new, old fashioned and artificial.

The third method featured a set of questions that could simply be answered with 'yes' or 'no'. These questions were based on the questionnaire designed specifically for children (up to 15 years old) by [18] to investigate emotional attachment with the robotic pet dog AIBO after interaction. The 6 questions address cognition (questions 1 and 2), emotional attachment (questions 3 and 4) and social reciprocity (questions 5 and 6).

TABLE II.

QUESTIONS FROM WEISS 2009

1. Do you think PLEO can see you?

2. Do you tink PLEO can undestand you?

3. Do you tink PLEO is happy if you strok him?

4. Do you tink PLEO can be sad (e.g. if hi/she is alone)?

5. Could PLEO be your playfellow?

6. Would you fell better, if PLEO is with yu when you are at home alone?

\section{5) Systematic observation}

An ad hoc coding scheme was built-up in order to carry out the analysis of the videotaped sequences to measure the occurrence and amount of time spent on the predefined key behaviors. To increase the intra and interrater reliability the manual coding was carried out by two of the experimenters working together.

The coding scheme is made up of 27 criterions, classified into 5 groups: Emotions, Verbal, Distance, Physical Contact, Gaze and Other Interactive Behavior (Table III). Psychological state variables (Emotions) and Verbal behaviour are not analysed in this work. The analyses focus on micro behaviours that have the advantage to be well identifiable low level and action/movement categories (Dautehnhan and Weary 2002) such as "Show something" or "Stroke". Furthermore micro behavior categories are less context dependent (may be applied to other robots and other situations) and thus may easily be adapted to other humanrobot interaction contexts and to other kind of robots. The behavior analyzed in this study is shadowed in Table III.

Provided that these lower level actions cannot describe the children play in terms of meaningful activity (a sequence of motions-actions with a purpose) we also linked them to one of 3 categories related to the social dimensions of the action: Affection, Reciprocity or Artifact, according to the classification proposed by [38].

Into the category of Affection we classified all the behaviors that related to modifying the robot's mood or wellbeing (petting, stroking, hitting), Reciprocity attempts at reciprocal interaction (i.e. commanding or offering as a request for partner's behavior), and Artifact when the robot was treated as an object. These categories would be closer to the construct of social presence than the low-level behavior taken individually. Both levels of analyses are reviewed in the next sections. 
TABLE III. CODING SCHEME

\begin{tabular}{|c|c|c|}
\hline Group & Behavior & Analitic Category \\
\hline Emotions & $\begin{array}{l}\text { Enjoyment } \\
\text { Boredom } \\
\text { Frustration } \\
\text { Neutral } \\
\text { Fear } \\
\end{array}$ & \\
\hline Verbal & $\begin{array}{l}\text { Vocalisation } \\
\text { Speak to PLEO } \\
\text { Speak to play-mate } \\
\text { Speak to adult } \\
\text { Speak (other) } \\
\end{array}$ & II Attempt at reciprocity \\
\hline Distance & $\begin{array}{l}\text { Within their grasp } \\
\text { Beyond their grasp }\end{array}$ & \\
\hline $\begin{array}{l}\text { Physical } \\
\text { contact }\end{array}$ & $\begin{array}{l}\text { Lift up } \\
\text { Hug } \\
\text { Pad } \\
\text { Stroke } \\
\text { Let down } \\
\text { Hold by the tail } \\
\text { Hit } \\
\text { Handle } \\
\text { Manipulation }\end{array}$ & $\begin{array}{l}\text { III Exploring as artifact / } \\
\text { I Affection } \\
\text { I Affection } \\
\text { I Affection } \\
\text { I Affection } \\
\text { I Affection } \\
\text { I Affection (negative) } \\
\text { I Affection (negative) } \\
\text { III Exploring as artifact } \\
\text { III Exploring as artifact }\end{array}$ \\
\hline Gaze & $\begin{array}{l}\text { Look at PLEO's area } \\
\text { Look at other } \\
\text { Look at adult } \\
\text { Eye-contact PLEO }\end{array}$ & $\begin{array}{l}\text { Orientation to interaction } \\
\text { Orientation others }\end{array}$ \\
\hline $\begin{array}{l}\text { Other } \\
\text { Interactive } \\
\text { behavior }\end{array}$ & $\begin{array}{l}\text { Show something } \\
\text { Grooming }\end{array}$ & $\begin{array}{l}\text { II Attempt at reciprocity } \\
\text { I Affection }\end{array}$ \\
\hline
\end{tabular}

IV. RESULTS

\section{A. Social Presence}

We calculated Cronbach's Alpha for the items of Social Presence and found it to be .74 for the five items. This means that Social Presence is a solid construct in this study (in social science, an alpha of at least .7 is considered an indication of a reliable construct [39]). Table IV presents the result of a Pearson correlation analysis. It shows that the score on Social Presence correlates with the score on Attitude, Emotional attachment and with the attribution of social adjectives. It also shows a negative correlation with age, indicating that the experience of a social entity is less strong for older children.

TABLE IV. CORRELATION OF QUESTIONNAIRE ITEMS

\begin{tabular}{|c|c|c|c|c|c|}
\hline & & Attitude & EmAtt & Social Adj. & Social Pres. \\
\hline \multirow[t]{2}{*}{ Age } & Corr &,- 093 &,- 028 &,- 255 &,$- 365 *$ \\
\hline & Sig. & ,333 & ,448 & 120 & , 040 \\
\hline \multirow[t]{2}{*}{ Attitude } & Corr & 1,000 & ,370* & ,173 & ,350* \\
\hline & Sig. & . & ,026 & 194 & ,034 \\
\hline \multirow{2}{*}{$\begin{array}{c}\text { Emotional } \\
\text { attachment }\end{array}$} & Corr & ,370* & 1,000 & ,274 & ,358* \\
\hline & Sig. & , 026 & & ,083 & ,031 \\
\hline \multirow[t]{2}{*}{ SocialAdj. } & Corr & ,173 & ,274 & 1,000 & $430 *$ \\
\hline & Sig. & 194 & ,083 & • & ,013 \\
\hline \multirow[t]{2}{*}{ Material Adj. } & Corr &,- 173 &,- 274 & $-1,000 * *$ &,$- 430 *$ \\
\hline & Sig. & 194 & ,083 & . & ,013 \\
\hline \multirow[t]{2}{*}{ Social Pres. } & Corr & ,350* & ,358* & ,430* & 1,000 \\
\hline & Sig. & ,034 & 031 & ,013 & . \\
\hline
\end{tabular}

\section{B. Interactive behavior}

To proceed to quantitative analyses, the behavior data were analyzed considering frequencies and durations of the 13 predetermined micro-behaviors and the higher level three dimensional category of modality (Table III). The metrics were frequencies for all criteria and duration in state behavior: Manipulation, Stroke, Show something and Look.

The behavior data were analyzed at an individual level to explore the covariation with social presence individual variable even though the play scenario was socially defined as playing with Pleo in couples. In this situation the individual behavior is assumed to be affected not only by individual variables (i.e. perceptions or beliefs) but as well by the dynamics of this situation (i.e. abortion of other's actions, dominance, regulatory actions as turn taking).

Results show great intersubject and inter-session variability. The most prevalent micro-behaviours are Stroke and Show something, both considering occurrences (see Table $\mathrm{V})$ and duration. For instance we can compare the differences in Fig.4 regarding the amount of time spent during the 8 minuts sessions to Affective Activity between children, from A1 (5 seconds) to J2 (340 seconds).

At an aggregated level, the activities on which children spent more time are affective and request for reciprocity, while using Pleo as an artifact occurred clearly less and little time is spend in. In Fig. 4 we can observe these differences when considering duration.

TARIE. V. MICRO-BF.HAVIOUR DF.SCRIPTIVFS

\begin{tabular}{lccc}
\hline & $\#$ & $\mathbf{x}$ & $\mathbf{s}$ \\
I Affection & & & \\
Grooming & 26 &, 93 & 1,359 \\
Hug & 5 &, 18 &, 945 \\
Pad & 5 &, 18 &, 945 \\
Stroke & 324 & 11,57 & 9,147 \\
Hold by tail & 0 & 0 & 0 \\
Hit & 16 &, 57 & 1,814 \\
II Reciprocity & & & \\
Show somth. & 569 & 20,32 & 12,335 \\
III Artifact & & & \\
Handle & 7 &, 25 &, 518 \\
Manipulation & 18 &, 64 & 1,026 \\
Others & & & \\
Look at other & 303 & 10,82 & 6,498 \\
Lift up & 41 & 1,46 & 2,899 \\
Let down & 35 & 1,25 & 2,271 \\
& & &
\end{tabular}

\# frequencies; $\mathrm{x}$ mean, s standard deviation

Exploration of covariation shows significance between age and micro-behavior Grooming and with Artifact modality by one side and with gender and Grooming and with Modality (rate) as showed in Tables VI and VII. 


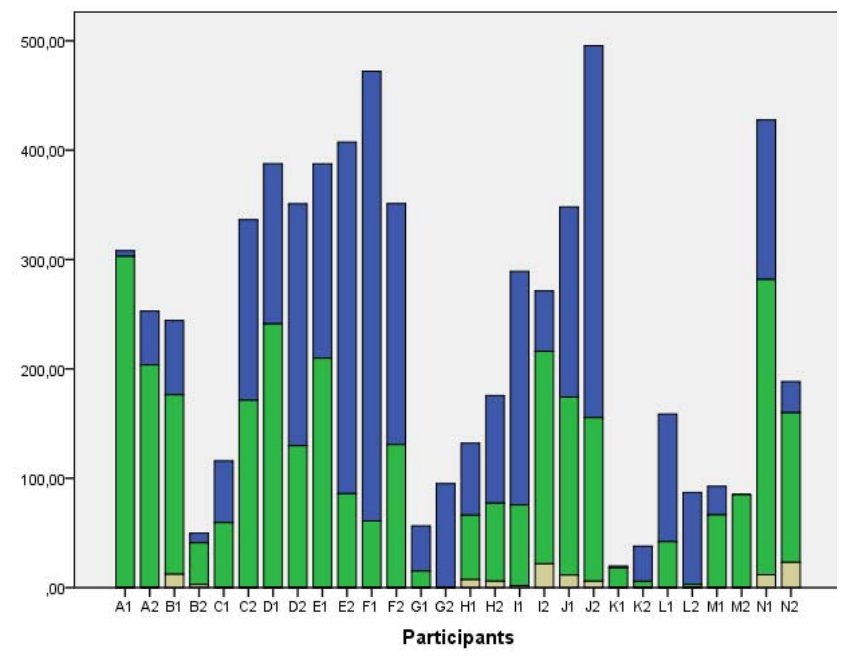

Figure 3. Playing time distribution (in seconds) between Modality categories Affection (blue), Reciprocity (green) and Artifact (grey)

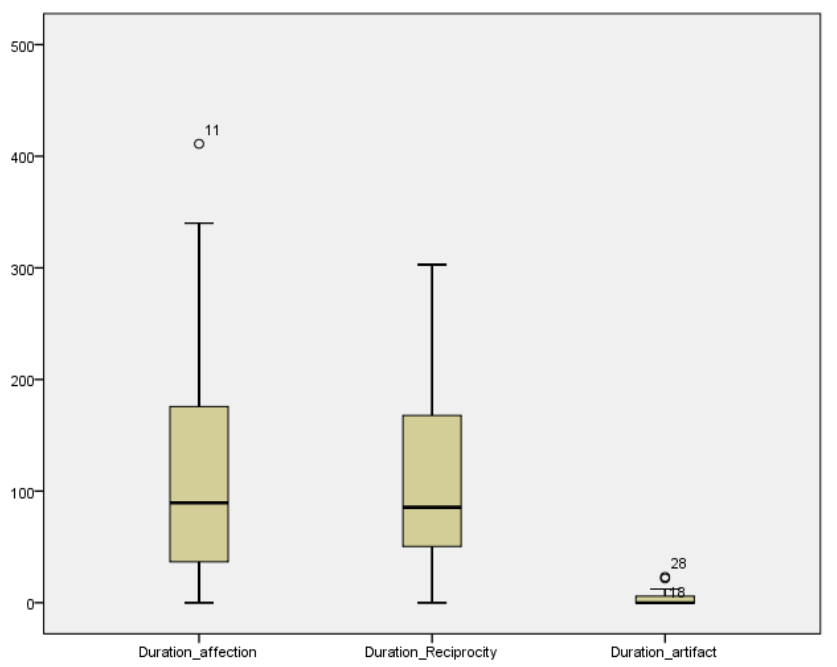

Figure 4. Boxplot of modality of interactive behaviour (duration)

TABLE VI. OBSERVED BEHAVIOR ITEMS

CORRELATION OF AGE WITH

\begin{tabular}{|l|r|r|r|r|r|}
\hline & \multicolumn{1}{|c|}{ GroomF } & GroomD & MeanAff & MeanR & MeanArt \\
\hline Corr &,$- 551^{* *}$ &,$- 523^{* *}$ &, 136 &, 346 &,$- 456^{*}$ \\
\hline Sig. &, 002 &, 004 &, 490 &, 071 &, 015 \\
\hline \multicolumn{7}{|c}{${ }^{*}<0.5$}
\end{tabular}

TABLE VII.

MANN WHITNEY U TEST FOR GENDER WITH OBSERVED BEHAVIOR ITEMS

\begin{tabular}{|l|r|r|r|r|r|r|}
\hline & Handle & $\begin{array}{l}\text { Grooming } \\
\text { frequency }\end{array}$ & $\begin{array}{l}\text { Grooming } \\
\text { distribution }\end{array}$ & $\begin{array}{l}\text { Rate } \\
\text { affection }\end{array}$ & $\begin{array}{l}\text { Rate } \\
\text { artifact }\end{array}$ & $\begin{array}{r}\text { Total n } \\
\text { Artifact }\end{array}$ \\
\hline U & 55,500 & 43,000 & 46,000 & 43,000 & 40,000 & 36,500 \\
\hline Sig. &, $039^{*}$ &, $017^{*}$ &, $027^{*}$ &, $037^{*}$ &, $015^{*}$ &, $008^{*}$ \\
\hline
\end{tabular}

\section{DISCUSSION AND CONCLUSIONS}

The results show that there are several ways to assess how children experience a robot, mainly from self-report and from behavior observation. Every approach contributes with complementary knowledge on children's beliefs and mental models regarding to social robots and interactive behavior. However, assessing constructs such as Social Presence cannot be drawn straight from micro-behaviours but from contextdependent purposeful activities that require broader analytical categories - based in social dynamics models - and interpretation for coding.

Further effort might be dedicated to building theory based code systems to classify interactive behaviors and measuring the amount of social engagement children are experiencing. However, the wide array of sociable robots with different appearances and featuring different resources for communication - social affordances [7] - make the transference of coding systems and the comparison of results difficult.

One of the limitations in the study is that participants have previous experience with robots in general and with Pleo specifically. All of them were attending a workshop on robotics at school, so they have been taught what robots are and how they work, have been exposed to demonstrations and had played with Pleo at least once before the observation. This participants' experience influences results in at least two ways: because their familiarity with Pleo we were neither able to explore the first impression of naïve users nor the dynamics of intuitive interactive behavior. Moreover, the participants supposedly had a more accurate and realistic understanding about robots structure and functionalities than the general population of children in this age. Generalizations to children's behavior with robots thus cannot be drawn from this small size sample.

Further research could focus on establishing the influence of age, gender and perhaps additional factors like experience on both behavior and on social presence.

\section{ACKNOWLEDGMENT}

The authors appreciate the collaboration of the school Col-legi Montserrat from Barcelona (http://www.cmontserrat.org/) to host the activities, and M. Montserrat del Pozo as its general director to permit them.

\section{REFERENCES}

[1] K. Dautenhahn, I. Werry, J. Rae, P. Dickerson, P. Stribling and B. Ogden, '"Robotic Playmates: Analysing Interactive Competencies of Children with Autism Playing with a Mobile Robot," in K. Dautenhahn, A. Bond, L. Canamero \& B Edmonds (eds), Socially Intelligent Agents- Creating Relationships with Computers and Robots. Multiagent Systems, Artificial Societies, and Simulated Organizations, vol. 3, Kluwer Academic Publishers, 2002, ch. 14, pp. 117-124.

[2] B. Robins, K. Dautenhahn, R. Te Boekhorst and A. Billard, "Robotic assistants in therapy and education of children with autism: can a small humanoid robot help encourage social interaction skills?,” Universal Access in the Information Society (UAIS), vol. 4 Issue 2, Dec. 2005

[3] M. A. Goodrich et al., "A case for low-dose robotics in autism therapy”, in Proc. HRI 2009, 2009, pp. 143-144. 
[4] E. Ferrari et al., "Therapeutic and educational objectives in Robot Assisted Play for children with autism," in Proc. 18th Int Symposium on Robot and Human Interactive Communication, RO-MAN vol. 2009, pp. 108-114.

[5] Hok Kwee, Jacques Quaedackers, Esther van de Bool, Lizette Theeuwen, Lucianne Speth Adapting the control of the MANUS manipulator for persons with cerebral palsy: An exploratory study.Technology and Disability. Volume 14, Number 1/2002

[6] J. Saldien, "ANTY: The development of an intelligent huggable robot for hospitalized children", 9th International Conference on Climbing and Walking Robots and the Support Technologies for Mobile Machines, September 12 - 14, 2006, Brussels, Belgium.

[7] Díaz, M. [et al.]. Building up child-robot relationship: from initial attraction towards long-term social engagement. A: HRI 2011. "2011 Human Robot Interaction. Workshop on Expectations in intuitive human-robot interaction". Lausanne: 2011, p. 17-22.

[8] M. Díaz, J. Sàez, D. Pardo and C. Angulo, "Pet robots with social skills for satisfactory interaction with hospitalized children”, Proceedings of RSS 2010 Workshop Learning for Human-Robot Interaction Modeling in Robotics: Science and Systems Conference.

[9] F. Tanaka, A. Cicourel , and J. R. Movellan, "Socialization between toddlers and robots at an early childhood education center" in Proc. The National Academy of Sciences PNAS, vol. 104, no. 46, 2007, pp. 17954-17958.

[10] F. Michaud, T. Salter PhD, A. Duquette and J-F Laplante, "Perspectives on Mobile Robots as Tools for Child Development and Pediatric Rehabilitation,” Assistive Technology: The Official Journal of RESNA, vol. 19:1, 2007, pp. 21-36.

[11] B. Caci, A. D'amico and M. Cardaci, "New Frontiers for Psychology and Education: Robotics,” Psychological Reports: vol. 94, Issue pp. 1372-1374, 2004.

[12] Libin, A.V. and E.V. Libin, Person-robot interactions from the robopsychologists' point of view: the robotic psychology and robotherapy approach. Proceedings of the IEEE, 2004. 92(11): p. 1789-1803

[13] Wada, K. and T. Shibata. Robot therapy in a care house-Its sociopsychological and physiological effects on the residents. in ICRA. 2006. Orlando, Florida, USA.

[14] Demers, L., et al., An international content validation of the Quebec User Evaluation of Satisfaction with assistive Technology (QUEST). Occupational Therapy International, 1999. 6(3): p. 159-175.

[15] Tam, C., et al., Movement-to-music computer technology: a developmental play experience for children with severe physical disabilities. Occupational Therapy International, 2007. 14(2): p. 99112

[16] Bartneck, C., Nomura, T., Kanda, T., Suzuki, T. and Kato, K. Cultural Differences in Attitudes Towards Robots. in Proceedings of the AISB Convention: Symposium on Robot Companions. 2005.Barker, J. and S. Weller, "Is it fun?" Developing children centred research methods. International Journal of Sociology and Social Policy, 2003. 23(1/2): p. 33-58.

[17] Scott, J., Children as respondents - the Challenge for Quantitative Methods, in Research with children: Perspectives and practices, P.M. Christensen and A. James, Editors. 2008, Taylor \& Francis.

[18] Weiss, A., Wurhofer, D., and Tscheligi, M. "I love this dog" Childrens' emotional attachment to the robotic dog AIBO. Special issue on the Human Robot Personal Relationship Conference in the International Journal of Social Robotics 1, 3 (August 2009), 243-248.

[19] Reeves B, Nash C (1996) The media equation: how people treat computers, televisions, and new media as real people and places. Cambridge University Press, New York

[20] DiSalvo CF, Gemperle F, Forlizzi J, Kiesler S (2002) All robots are not created equal: the design and perception of humanoid robot heads. In: Proceedings of the conference on Designing intera

[21] Lee, K.M. and C. Nass. Designing social presence of social actors in human computer interaction. in Proceedings of the SIGCHI conference on Human factors in computing systems. 2003. Fort Lauderdale, Florida, USA.Bickmore, T. and D. Schulman. The Comforting Presence of Relational Agents. in Proceedings of CHI. 2006. Montréal, Québec, Canada.

[22] Heerink M, Kro“se BJA, Wielinga BJ, Evers V (2007) Observing conversational expressiveness of elderly users interacting with a robot and screen agent. In: Proceedings international conference on rehabilitation robotics (ICORR), Noordwijk, The Netherlands

[23] Witmer BG, Singer MJ (1998) Measuring presence in virtual environments: a presence questionnaire. Presence 7(3):225-240

[24] Lombard, M. and T.B. Ditton, At the heart of it all: The concept of presence. Journal of Computer-Mediated-Communication, 1997. 3(2): p. Available online: http://www.ascusc.org/jcmc/vol3/issue2/lombard.html.Wagner HL, Smith J (1991) Facial expression in the presence of friends and strangers. J Nonverbal Behav 15(4):201-214

[25] Lee, V. and H. Wagner, The Effect of Social Presence on the Facial and Verbal Expression of Emotion and the Interrelationships Among Emotion Components. Journal of Nonverbal Behavior, 2002. 26(1): p. 3-25.

[26] Nakano, Y.I. and T. Nishida. Awareness of Perceived World and Conversational Engagement by Conversational Agents. in AISB 2005 Symposium: Conversational Informatics for Supporting Social Intelligence \& Interaction. 2005. Hatfield, UK.

[27] Heerink, M., et al., Influence of Social Presence on Acceptance of an Assistive Social Robot and Screen Agent by Elderly Users. Advanced Robotics, 2009c. 23(14): p. 1909-1923.

[28] Heerink, M., et al., The Influence of Social Presence on Acceptance of a Companion Robot by Older People. Journal of Physical Agents Special Issue on Human interaction with domestic robots, 2008b. 2(2): p. 33-40.

[29] K. Pitsch, B. Koch, "How infants perceive the toy robot pleo. an exploratory case study on infant-robot-interaction”, Second International Symposium on New Frontiers in Human-RobotInteraction (AISB), SSAISB: The Society for the Study of Artificial Intelligence and the Simulation of Behavior, Leicester, UK, 2010.

[30] S. Fransen, P. Markopoulos, “Let robots do the talking”, IDC '10: Proceedings of the 9th International Conference on Interaction Design and Children, ACM, New York, NY, USA, 2010, pp. 59-68.

[31] Y. Fernaeus, M. Hªkansson, M. Jacobsson, S. Ljungblad, "How do you play with a robotic toy animal?: a long-term study of pleo", IDC '10: Proceedings of the 9th International Conference on Interaction Design and Children, ACM, New York, NY, USA, 2010, pp. 39-48.

[32] M. Jacobsson, "Play, belief and stories about robots: A case study of a pleo blogging community”, International Symposium on Robot and Human Interactive Communication (RO-MAN), Toyama, Japan, 2009.

[35] Bailenson JN, Blascovich J, Beall AC, Loomis JM (2001) Equilibrium revisited: mutual gaze and personal space in virtual environments. Presence Teleoper Virtual Environ 10:583-598

[36] Forlizzi, J., F. Gemperle, and C. DiSalvo. Perceptive Sorting: A Method for Understanding Responses to Products. in Proceedings of the 2003 international conference on Designing pleasurable products and interfaces. 2003.

[37] Faye, P., et al., An alternative to external preference mapping based on consumer perceptive mapping. Food Quality and Preference, 2006. 17(7-8): p. 604-614.

[38] Melson GF, Peter H. Kahn PH Jr, Beck, AM, Friedman B. 2009. Robotic pets in human lives: implications for the human-animal bond and for human relationships with personified technologies. Journal of Social Issues 65(3): 545-567.

[39] Nunnaly, J.C. and I.H. Bernstein, Psychometric theory. 1978, New York: McGraw-Hill 